\title{
The evolution of invasive pulmonary aspergillosis on chest imaging in response to antifungal therapy
}

\author{
Woon H Chong, ${ }^{1}$ Ammoura Ibrahim, ${ }^{2}$ Biplab Kumar Saha ${ }^{3}{ }^{3}$
}

${ }^{1}$ Pulmonary and Critical Care Medicine, Albany Medical Center, Albany, New York, USA ${ }^{2}$ Department of Pathology, Albany Medical Center, Albany, New York, USA

${ }^{3}$ Pulmonary and Critical Care Medicine, Ozarks Medical Center, West Plains, Missouri, USA

\section{Correspondence to} Dr Biplab Kumar Saha; spanophiliac@yahoo.com

Accepted 10 March 2021

Check for updates

(c) BMJ Publishing Group Limited 2021. No commercial re-use. See rights and permissions. Published by BMJ.

\begin{tabular}{l}
\hline To cite: Chong WH, \\
Ibrahim A, Saha BK. BMJ \\
Case Rep 2021;14:e242576. \\
doi:10.1136/bcr-2021- \\
242576 \\
\hline
\end{tabular}

\section{DESCRIPTION}

A 78-year-old man presented with 1-month symptoms of dyspnoea and non-productive cough. He was initially diagnosed with biopsy-confirmed ulcerative colitis on a colonoscopy about 4-month ago. He was treated with intravenous methylprednisolone without any clinical improvement and required intravenous infliximab for remission. $\mathrm{He}$ was eventually discharged on an oral prednisone taper regimen and scheduled infliximab infusion. His tuberculin skin test was negative before the initiation of infliximab. Laboratory workup involving complete blood count and comprehensive metabolic panel (CMP) were within normal limits. His chest imaging (figure 1A) on admission revealed diffuse, bilateral nodular lesions, with halo signs. Empirical antifungal therapy of intravenous voriconazole was initiated due to concerns of invasive pulmonary aspergillosis (IPA). Infectious workup, including serum beta-D-glucan and galactomannan, returned negative. Bronchoscopy with transbronchial biopsy was performed (figure 2) that revealed numerous slender and septate hyphae branching at acute angles with tissue invasion on $\mathrm{H} \& \mathrm{E}$ and Grocott methenamine silver stain consistent with IPA. His infliximab was held, and he was cautiously tapered off his oral prednisone. After 3 weeks of voriconazole therapy, he reported progressive dyspnoea and found to have elevated liver enzymes on CMP, despite voriconazole trough levels consistently maintained at a therapeutic level of $1.0-5.5 \mu \mathrm{g} / \mathrm{mL}$. Repeat chest imaging (figure $1 \mathrm{~B}$ ) revealed progressive enlargement of known diffuse nodular lesions with the development of cavitary lesions and new appearing nodular lesions, concerning for failure of voriconazole therapy in the setting drug-related hepatotoxicity. A decision was made to transition to isavuconazonium sulfate therapy. Repeat chest imaging in 3 weeks (figure 1C) demonstrated the stability of multiple mass-like cavitary lesions where some have regressed in size without new appearing nodular lesions. He continued to improve clinically with serial chest imaging (figure $1 \mathrm{D}, \mathrm{E}$ ), showing regression of his known IPA-related lung lesions. He suffered from no drug-related adverse events and eventually transitioned to oral isavuconazonium sulfate therapy to complete a total 9-month duration of antifungal therapy as an outpatient.

In the early stages of IPA, radiographic imaging will display nodules, consolidations, halo signs and wedge-shaped infarcts. ${ }^{1}$ Halo sign is defined radiologically as areas of ground-glass opacities (GGO) with surrounding nodules representing pulmonary infarct surrounded by alveolar haemorrhage from tissue invasion and occlusion of small and mediumsized pulmonary arteries by Aspergillus species on histopathology. ${ }^{2}$ Halo sign is commonly seen within the first 2 weeks of IPA infection in up to $61 \%$ of patients regardless of immunodeficiency status. ${ }^{34}$ CT imaging may demonstrate GGO/consolidation surrounding the initial nodule as local inflammation

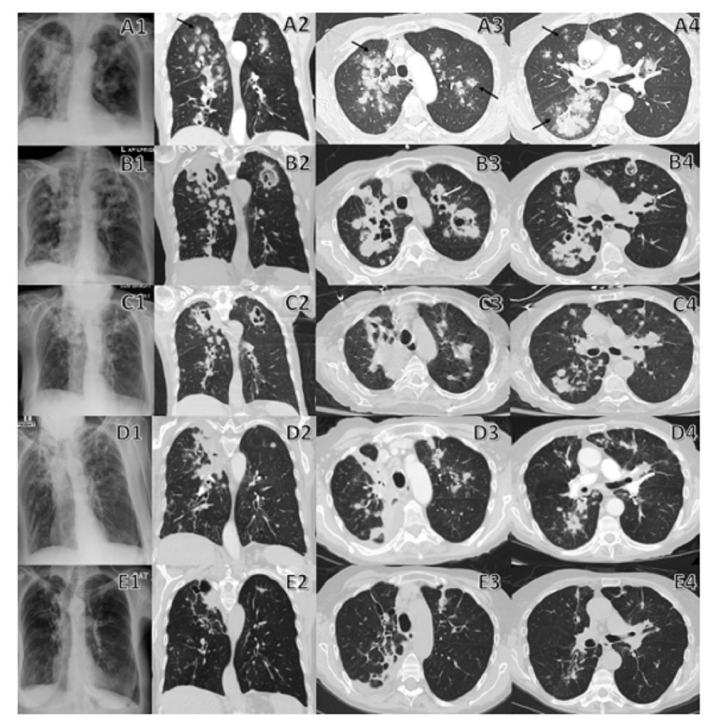

Figure 1 Comparison between initial and follow-up chest imaging. A1-A4 are chest radiograph and $\mathrm{CT}$ on admission that demonstrate diffuse nodular lesions in a bronchovascular distribution with halo sign (black arrow) and cavitary lesions. B1-B4 are chest radiograph, and CT performed 3 weeks after initiation of voriconazole therapy revealing progression of initial diffuse nodular lesions which have enlarge/coalesce together to form multiple irregular consolidative masses and many have developed cavitary lesions with air crescent sign (white arrow). There are also new nodular lesions when compared with previous chest imaging. C1-C4 are chest radiograph, and CT performed 3 weeks after initiation of isavuconazonium sulfate therapy that shows the stability of multiple mass-like cavitary lesions where some have regressed in size without new appearing nodular lesions. D1-D4 are chest radiograph, and CT repeated 2 months after initiation of isavuconazonium sulfate therapy showing further regression of multiple masslike/nodular lesions into linear/wedged-shaped lesions with volume loss. E1-E4 are chest radiograph, and CT repeated 7 months after initiation of isavuconazonium sulfate therapy revealing residual lesions with almost complete resolution of multiple mass-like/nodular lesions into smaller linear lesions, thin-walled cysts and dilated airways (bronchiectasis) that resemble scarring (fibrosis) of lung parenchyma and airways. 


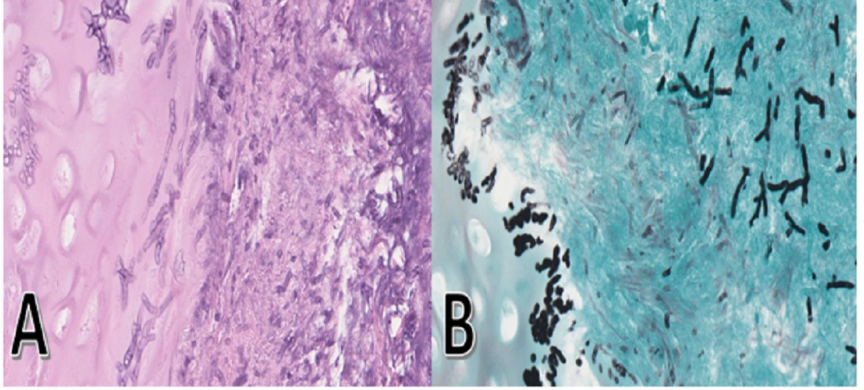

Figure 2 (A) Transbronchial biopsy of right upper lobe reveals numerous slender and septate hyphae that branch at acute angles in the subepithelial stroma and cartilage with tissue invasion on $\mathrm{H} \& \mathrm{E}$ stain. (B) Grocott methenamine silver stain demonstrated hyphal organisms stained in black with characteristic branching at acute angles compatible with Aspergillus species morphologically.

increases and may coalesce into larger consolidations. ${ }^{2}$ An observational study showed that in 50\% of IPA, the volume of lesions, including consolidation displayed on CT scan, might increase fourfold during the first week of effective antifungal therapy and remained stable during the second week. ${ }^{3}$ Cavitation may occur with an air crescent sign, defined as a peripheral crescentic collection of air surrounding a pulmonary nodule signifying the separation of the devitalized necrotic lung from adjacent lung parenchyma after Aspergillus invasion. ${ }^{2}$ It is usually seen 2-3 weeks after treatment initiation or concurrent resolution of immunodeficiency in up to $50 \%$ of patients with IPA. ${ }^{23}$ Air crescent signs and cavitation should not be equated with IPA progression as they are dependent on neutrophil recovery that facilitates the formation of necrosis and is associated with improved treatment response and survival. ${ }^{25}$ Cavities may take up to 8 months to resolved entirely or formed linear scar and a thin-walled cyst that symbolise remote IPA infection. ${ }^{2}$ Radiological improvement can often be equated with adequate IPA response to treatment. ${ }^{5}$ In the absence of neutropenia or immunosuppressive therapy inducing neutrophil dysfunction, the CT manifestation of halo sign, cavitation and air crescent sign can be absent, especially in critically ill patients. ${ }^{6}$ The initiation of antifungal therapy during the early onset of IPA with halo signs and nodules on imaging is associated with improved treatment response and survival. ${ }^{4}$

The initial therapy for patients with IPA is monotherapy of either voriconazole or isavuconazonium sulfate. Multiple studies demonstrated that voriconazole is superior to amphotericin B in IPA with improved survival, better tolerability and less adverse events. ${ }^{78}$ A retrospective study by Herbrech et al showed that the complete and partial response rate in the voriconazole group was $53 \%$ compared with the amphotericin B group at 32\% over 3 months in IPA. ${ }^{7}$ Visual toxicities are often associated with the initial use of voriconazole, where it is frequently transient and self-limiting, where a change in therapy should be considered if persistent or severe visual disturbances occur. ${ }^{78}$ Therefore, therapeutic drug monitoring for voriconazole is recommended to ensure adequate drug efficacy and safety in IPA where trough levels are obtained on days five to seven when pharmacokinetic steady state is achieved. ${ }^{9}$ Isavuconazonium sulfate has been shown to have better tolerability and similar efficacy with a lower risk of visual disturbances and hepatotoxicity than voriconazole when treating invasive fungal disease. ${ }^{10}$ Furthermore, routine therapeutic drug monitoring for isavuconazonium sulfate is unnecessary as studies have shown a lack of increase in the risk of drug toxicity or decrease in antifungal efficacy. Amphotericin
Patient's perspective

TIP: This is an important section and gives the patient/close family the opportunity to comment on their experience. This enhances the case report and is strongly encouraged.

\section{Learning points}

- Given the significant morbidity and mortality associated with invasive pulmonary aspergillosis (IPA), a presumptive diagnosis can be made based on clinical presentation and radiographic imaging, where antifungal therapy should be initiated even before microbiological and histopathological confirmation.

- In immunocompromised patients with fever and lung infiltrates who do not respond to antibiotics, halo signs can be an early indicator for IPA requiring prompt institution of antifungal therapy.

- Cavitation and air crescent signs are commonly seen 2 weeks after initiating treatment or resolution of immunodeficiency status.

- Despite being highly suggestive of IPA in the appropriate clinical setting, the diagnostic utility of air crescent sign is limited by its late appearance on CT imaging.

$\mathrm{B}$ is often considered in cases of refractory IPA or suspicion for azole drug resistance.

Contributors WHC, Al and BKS were involved in planning, collection of data, preparation of the initial and final manuscript.

Funding The authors have not declared a specific grant for this research from any funding agency in the public, commercial or not-for-profit sectors.

Competing interests None declared.

Patient consent for publication Not required.

Provenance and peer review Not commissioned; externally peer reviewed.

ORCID iD

Biplab Kumar Saha http://orcid.org/0000-0002-3595-8804

\section{REFERENCES}

1 El-Baba F, Gao Y, Soubani AO. Pulmonary aspergillosis: what the generalist needs to know. Am J Med 2020;133:668-74.

2 Abramson S. The air crescent sign. Radiology 2001;218:230-2.

3 Caillot D, Couaillier JF, Bernard A, et al. Increasing volume and changing characteristics of invasive pulmonary aspergillosis on sequential thoracic computed tomography scans in patients with neutropenia. J Clin Oncol 2001;19:253-9.

4 Greene RE, Schlamm HT, Oestmann J-W, et al. Imaging findings in acute invasive pulmonary aspergillosis: clinical significance of the halo sign. Clin Infect Dis 2007;44:373-9.

5 Segal BH, Herbrecht R, Stevens DA, et al. Defining responses to therapy and study outcomes in clinical trials of invasive fungal diseases: mycoses Study Group and European organization for research and treatment of cancer consensus criteria. Clin Infect Dis 2008;47:674-83.

6 Meersseman W, Lagrou K, Maertens J, et al. Invasive aspergillosis in the intensive care unit. Clin Infect Dis 2007;45:205-16.

7 Herbrecht R, Denning DW, Patterson TF, et al. Voriconazole versus amphotericin B for primary therapy of invasive aspergillosis. N Engl J Med 2002;347:408-15.

8 Walsh TJ, Pappas P, Winston DJ, et al. Voriconazole compared with liposomal amphotericin $\mathrm{B}$ for empirical antifungal therapy in patients with neutropenia and persistent fever. N Engl J Med 2002;346:225-34.

9 Pascual A, Calandra T, Bolay S, et al. Voriconazole therapeutic drug monitoring in patients with invasive mycoses improves efficacy and safety outcomes. Clin Infect Dis 2008:46:201-11.

10 Maertens JA, Raad II, Marr KA, et al. Isavuconazole versus voriconazole for primary treatment of invasive mould disease caused by Aspergillus and other filamentous fungi (secure): a phase 3, randomised-controlled, non-inferiority trial. Lancet 2016;387:760-9. 
Copyright 2021 BMJ Publishing Group. All rights reserved. For permission to reuse any of this content visit https://www.bmj.com/company/products-services/rights-and-licensing/permissions/

BMJ Case Report Fellows may re-use this article for personal use and teaching without any further permission.

Become a Fellow of BMJ Case Reports today and you can:

- Submit as many cases as you like

- Enjoy fast sympathetic peer review and rapid publication of accepted articles

Access all the published articles

Re-use any of the published material for personal use and teaching without further permission

Customer Service

If you have any further queries about your subscription, please contact our customer services team on +44 (0) 2071111105 or via email at support@bmj.com.

Visit casereports.bmj.com for more articles like this and to become a Fellow 